\title{
Immunological Aspects of Diagnosis and Management of Childhood Tuberculosis
}

This article was published in the following Dove Press journal:

Infection and Drug Resistance

\author{
Luis Horacio Gutiérrez- \\ González $\mathbb{D}^{\prime}$ \\ Esmeralda Juárez ${ }^{2}$ \\ Claudia Carranza ${ }^{2}$ \\ Laura E Carreto-Binaghi ${ }^{2}$ \\ Alejandro Alejandre ${ }^{3}$ \\ Carlos Cabello-Gutiérrrez' \\ Yolanda Gonzalez (D) ${ }^{2}$ \\ 'Virology and Mycology Department, \\ National Institute for Respiratory \\ Diseases Ismael Cosío Villegas, Mexico \\ City, Mexico; ${ }^{2}$ Microbiology Department, \\ National Institute for Respiratory \\ Diseases Ismael Cosío Villegas, Mexico \\ City, Mexico; ${ }^{3}$ Pediatric Clinic, National \\ Institute for Respiratory Diseases Ismael \\ Cosío Villegas, Mexico City, Mexico
}

\begin{abstract}
The diagnosis of tuberculosis (TB) in children is difficult because of the low sensitivity and specificity of traditional microbiology techniques in this age group. Whereas in adults the culture of Mycobacterium tuberculosis (M. tuberculosis), the gold standard test, detects $80 \%$ of positive cases, it only detects around $30-40 \%$ of cases in children. The new methods based on the immune response to M. tuberculosis infection could be affected by many factors. It is necessary to evaluate the medical record, clinical features, presence of drug-resistant M. tuberculosis strains, comorbidities, and BCG vaccination history for the diagnosis in children. There is no ideal biomarker for all TB cases in children. A new strategy based on personalized diagnosis could be used to evaluate specific molecules produced by the host immune response and make therapeutic decisions in each child, thereby changing standard immunological signatures to personalized signatures in TB. In this way, immune diagnosis, prognosis, and the use of potential immunomodulators as adjunct TB treatments will meet personalized treatment.
\end{abstract}

Keywords: TB, immune status, diagnosis, TB-treatment, coinfections, personalized diagnosis

\section{Introduction}

Tuberculosis (TB) is a global health problem ${ }^{1}$ with presentations and outcomes that differ between children and adults and with children being at a higher risk of rapid progression to active TB. ${ }^{2}$ The Calmette-Guerin bacillus (BCG) vaccine confers protection from severe forms of $\mathrm{TB}$ in children. However, it does not prevent primary infection and, more importantly, does not prevent reactivation of latent pulmonary infection. ${ }^{3}$ The World Health Organization (WHO) estimates that children under 15 years accounted for $11 \%$ of all TB cases in $2018 .^{4}$ Nevertheless, the global impact of childhood TB has only been estimated from the adult disease, ${ }^{5}$ and not adequately assessed in every different pediatric population. ${ }^{6}$ Particularly in young children, early recognition of TB is critical to define the patient's prognosis; thus, clinical trials including pediatric TB patients are necessary to define the best diagnostic and therapeutic approaches. ${ }^{6}$

TB clinical features in children are unspecific, and symptoms can mimic common childhood diseases as bacterial, viral or fungal infections, and malnutrition. ${ }^{7}$ The detection of Mycobacterium tuberculosis (M. tuberculosis), an intracellular pathogen that affects mainly the lungs, is a challenging task in children due to the difficulty in accessing biological samples for microbiological tests. Newborns and children up to 2 years old do not produce sputum in the amounts
Correspondence: Yolanda Gonzalez Microbiology Department, National Institute for Respiratory Diseases Ismael Cosío Villegas, Calzada de Tlalpan 4502, Sección XVI, Alcaldía de Tlalpan, 14080, Mexico City, México

Tel +52 555487 I 700 Ext. 5 II 17

Email ygonzalezh@iner.gob.mx
Infection and Drug Resistance 2021:14 929-946 
required for bacteria identification. Other samples, such as gastric washings, are positive only in $10-15 \%$ of samples due to the paucibacillary disease usually presented in children. The culture of M. tuberculosis is the gold standard in adults, but, in children, cultures remain negative in around $70 \%$ of cases with suspected $\mathrm{TB}^{7}$

Both biomarkers and immunological signatures based on immune response have been proposed to predict TB susceptibility, diagnosis, and treatment outcomes in children. ${ }^{8}$ However, immunological signatures of TB based on either gene expression or functional immune pathways are a challenge in children, because of many factors impact on the expression of these biomarkers, including the genetic background, the immune system maturation associated to age and nutrition status, drugresistant $M$. tuberculosis strains, coinfections, BCG vaccination, and clinical features. The vast array of clinical and immunological features of TB in children points to personalized medicine rather than a one-for-all therapy.

\section{Diagnosis Based on Clinical Features of TB in Children}

Following pulmonary TB initial infection, the induction of adaptive immunity mediated by a $\mathrm{T}$ cell-dependent response limits the infection's progress. However, several endogenous or exogenous factors might alter the defense mechanisms and favor bacillary multiplication and development of disease. ${ }^{9-11}$ Initial infection may lead to an acute disease with or without extrapulmonary manifestations, or a latent TB state. The infection in most children remains latent, and if environmental and host conditions are adequate, it can evolve to the active disease at any time of life. ${ }^{1}$

Diagnosis and disease progression are among the most critical issues in TB in children. The difficulty of distinguishing between latent infection and disease, and the difficulty of microbiological isolation because of children's paucibacillary condition are significant concerns. TB disease in children is insidious, with nonspecific clinical data and low likelihood of recovering the bacillus; thereby, the difficulties in diagnosis. In children, primary TB is more frequent than reinfection by intra or extradomiciliary contact with an adult with active disease, and the pulmonary form is the primary clinical expression, although extrapulmonary forms also occur. ${ }^{11,12}$ The vast array of clinical features contributes to the complexity of the disease.
Children with TB infection may be asymptomatic or with few symptoms. Infants and children $>10$ years old are more likely to present symptoms, the most common being fever, weight loss, decay, and respiratory manifestations. The latter will depend on the clinical form and the extent of the lesion. In primary $\mathrm{TB}$, symptoms are initially scarce; however, with the enlargement of mediastinal nodes, signs of airway compression, such as cough and wheezing (the main symptoms during this period), may be found; bronchoalveolar rales may present later. ${ }^{13}$ Physical examination findings vary according to the patient's age and the timing of evaluation. ${ }^{14}$ Older children and adolescents may present the primary form or pulmonary TB, similar to adults, with the classic bacillary impregnation syndrome (cough, asthenia, adynamia, anorexia, night sweats, chills, weight loss, and fever), pulmonary cavitation and, exceptionally, hemoptysis. During this period, smear sputum is usually positive. However, some patients might show fewer symptoms, such as chronic cough (frequent in preschool and school children) or otherwise unexplainable weight loss. ${ }^{15-18}$ The presence of erythema nodosum, phlyctenular keratoconjunctivitis, and, less frequently, apathy or recurrent diarrhea that do not respond to usual treatment also suggests TB. ${ }^{11}$ Most signs and symptoms improve within several weeks of starting treatment, although the cough may last several months. As expected, childhood radiographic TB findings are quite different from those of the adults, especially the size and importance of lymphadenitis. ${ }^{19}$ Caseous pneumonia is one of the complications of TB, which invades all tissues and occupies lung areas; ${ }^{20}$ the central lesion comprises softened tissue that can open to draining bronchi and the airways, with the consequent spread to the pleural cavity and the formation of bronchopleural or tracheoesophageal fistulae, pyopneumothorax, acute constrictive pericarditis, or esophagus rupture. ${ }^{21,22}$

In 2013, the WHO developed guidelines for TB, whose primary goal is to eliminate childhood TB in highincidence countries. The recommended options include the screening of those children who have had close contact with a TB patient, HIV-infected patients, and those with poor health care access. ${ }^{18}$ For children, TB is mainly diagnosed by identifying symptoms and HIV status. In low-incidence countries, children with $\mathrm{TB}$ are usually identified in one of three ways: suspecting TB as the cause of symptomatic pulmonary or extrapulmonary disease, identifying an asymptomatic child with pulmonary TB during an investigation of contacts from an adult TB 
case $50 \%$ of children are diagnosed this way in the United States), and running a community or school assessment program for $\mathrm{TB} .{ }^{23} \mathrm{~A}$ wrong decision in this step may lead to clinicians and patients to a dreadful prognosis of the disease. Before anti-tuberculosis therapy, the mortality rate for progressive primary pulmonary $\mathrm{TB}$ was $30-50 \%$; nowadays, the prognosis is excellent with effective treatment. However, there are significant discrepancies in clinical management guidelines for childhood TB worldwide, enhancing the need for a standard clinical practice based on well-conducted prospective studies. ${ }^{24}$

Because of the variety of clinical manifestations, TB in children would benefit from personalized medicine. Immunodiagnostics has been suggested, but TB in children is often a "silent" infection because of the low inflammatory response. ${ }^{25}$ The developing immune system in young children reacts to infection with $M$. tuberculosis with a broad array of patterns that would help the diagnosis and could also be used as biomarkers to follow the disease progression (Table 1).

\section{The Immune Response as an Immunological Signature in Children with TB}

The immune system is a complex interaction of cells that protects the body from microbes. The lung is the entrance of many particles, microbes, and pathogens, where the innate humoral and cellular responses become critical. However, in newborns and infants, the immune response is immature. ${ }^{26}$ Following infection, several factors determine the progression to active $\mathrm{TB}$, such as age, nutritional state, BCG status, and genetic defects. i) Age; children under three years are at the highest risk for rapid progression to active TB, while the lowest risk is found between 5 and 10 years - the so-called "safe school years". ${ }^{2}$ The frequency of CD4+ $\mathrm{T}$ cells specific for M. Tuberculosis ESAT-6 (Early Secretion Antigen Target-6) is lower in younger children ( $0-3$ years old) than in older children (3-15 years old). ${ }^{2}$ During puberty, the risk increases, especially in girls, ${ }^{27}$ because the host immunological responses to M. tuberculosis change with age and sexual maturation. Immunity goes from poorly functioning innate cells and a Th2 deviation in young children to an enhanced lymphocyte predominance and a Th1 bias in school children, and a total immune distortion due to sex hormones, assembling a more enhanced inflammatory response and a Th2 deviation in girls. ii) Nutritional state; TB prevalence among acutely malnourished children varies widely (2-$24 \%$ ) and, in these children, a high TB burden ${ }^{28}$ and lower levels of interferon-gamma (IFN- $\gamma$ ) in response to TB antigens were associated with malnutrition. ${ }^{29}$ iii) $\mathrm{BCG}$ vaccination; unvaccinated children have an increased risk for the more severe clinical forms of $\mathrm{TB}$, meningitis, and miliary $\mathrm{TB}^{3}$ and to develop active $\mathrm{TB}^{2}{ }^{2}$ iv) Genetic defects or inadequate innate or acquired immune responses are associated with TB development in children. ${ }^{30}$ Both the susceptibility to infection with $M$. tuberculosis and the active TB development in children involve a complex interaction of extrinsic and intrinsic factors, as well as the interaction of the pathogen with the host immune system (Figure 1).

Molecules of the innate and acquired immune system involved in the susceptibility to M. tuberculosis infection have been identified in children with genetic diseases. The Mendelian susceptibility to mycobacterial disease (MSMD) induces high susceptibility to infections by low virulence mycobacteria in children, such as BCG, but not to other pathogens. MSMD is associated with mutations in five autosomal genes: IFNGR (1 and 2), STAT1, IL12B, $I L 12 R B 1$, and NEMO. These genes are involved in the axes of IL-12/IL-23-dependent and IFN- $\gamma$-mediated immunity. ${ }^{31}$

IFN- $\gamma$ responses to mycobacterial antigens in BCGvaccinated infants are heterogeneous, with significant individual variation. ${ }^{32}$ The natural history of M. tuberculosis-infected children less than one year of age suggests they are at greater risk for progression to active TB than immunocompetent adults. The immature immune response in children has limited capability to control Mycobacterium infection. ${ }^{33}$ Children with active tuberculosis are often asymptomatic or have unspecific respiratory signs, and $M$. tuberculosis tends to grow uncontrolled; after that, the infection in many cases progresses to a caseating lesion, and Mycobacteria can spread, leading to meningitis or miliary disease forms. This occurs more often in infants and young children than in immune-competent adults. ${ }^{20}$ In vitro and in vivo studies showed that BCG-infected skin DCs induce the CD4+ and CD8+ $\mathrm{T}$ cells activation capable of secreting TNF- $\alpha$, IL-6, and IL-12. In newborns, BCG-specific $\mathrm{CD} 4+\mathrm{T}$ cells could be detected in the peripheral blood 3-10 weeks after vaccination. ${ }^{34}$ The IFN- $\gamma$ CD4 T cells are key to M. tuberculosis control, and M. tuberculosis antigens can induce it by vaccination or immunestimulation. 
Table I Factors Pointing Toward Personalized Diagnosis

\begin{tabular}{|c|c|c|c|c|c|}
\hline \multicolumn{5}{|c|}{ Standard Diagnosis of Pulmonary TB in Children } & \multirow[t]{2}{*}{ Ref. } \\
\hline & Clinical Features & $\begin{array}{l}\text { Microbiological } \\
\text { Tests Sensitivity }\end{array}$ & $\begin{array}{l}\text { DNA Tests } \\
\text { (Xpert MTB/ } \\
\text { RIF) } \\
\text { Sensitivity }\end{array}$ & $\begin{array}{l}\text { IFN-g Release } \\
\text { Assays (QFT- } \\
\text { Gold Sensitivity) }\end{array}$ & \\
\hline$<3$ years old & $\begin{array}{l}\text { Asymptomatic or few } \\
\text { symptoms. "Silent" } \\
\text { infection. Ghon focus, lymph } \\
\text { node disease. }\end{array}$ & $\begin{array}{l}\text { Less of } 40 \% \text {, even in } \\
\text { samples derived from } \\
\text { gastric aspirates and } \\
\text { induced sputum. }\end{array}$ & $\begin{array}{l}\text { Children < } \\
\text { I year is } 75 \% \text { in } \\
\text { gastric } \\
\text { aspirates }\end{array}$ & $\begin{array}{l}\text { Only } 54 \% \text { are } \\
\text { positively in part } \\
\text { by immature } \\
\text { immune response. }\end{array}$ & \multirow[t]{3}{*}{$2,13,15-18,25,62-64$} \\
\hline$<10$ years old & $\begin{array}{l}\text { Ghon focus, lymph node } \\
\text { disease, bronchial disease. }\end{array}$ & $\begin{array}{l}\text { Sputum smears: } \\
\text { about } 20 \% \text {. Cultures: } \\
<40 \% \text {. }\end{array}$ & $\begin{array}{l}>1-10 \text { years is } \\
100 \% \text { in gastric } \\
\text { aspirates and } \\
\text { induced } \\
\text { sputum. }\end{array}$ & About $1 \mathrm{I}-40 \%$. & \\
\hline $\begin{array}{l}\text { Older children and } \\
\text { adolescents }\end{array}$ & $\begin{array}{l}\text { Primary form or pulmonary } \\
\text { disease. Classic bacillary } \\
\text { impregnation syndrome, } \\
\text { cavitation and hemoptysis. }\end{array}$ & $\begin{array}{l}\text { Smear sputum is } \\
\text { usually positive }\end{array}$ & $\begin{array}{l}1 \mathrm{I}-<15 \text {, is } 89 \% \\
\text { in sputum. }\end{array}$ & $\begin{array}{l}\text { II-40\%. IGRAs } \\
\text { may be used to } \\
\text { help support the } \\
\text { diagnosis of active } \\
\text { TB. }\end{array}$ & \\
\hline \multicolumn{5}{|c|}{ Conditions that modify TB disease and standard diagnosis tools } & \\
\hline Age & \multicolumn{4}{|c|}{$\begin{array}{l}\text { Children under three years are at the highest risk for rapid progression to active TB, they have } \\
\text { a paucibacillary condition, non sputum. }\end{array}$} & \multirow[t]{6}{*}{$\begin{array}{l}2,3,25,27,28,30,32,39-4 I \\
48-50,56-63\end{array}$} \\
\hline Nutrition & \multicolumn{4}{|c|}{$\begin{array}{l}\text { Malnourished children have high TB burden. Malnutrition is associated with lower levels of IFN- } \\
\mathrm{g} \text { in response to TB antigens. }\end{array}$} & \\
\hline BCG vaccination & \multicolumn{4}{|c|}{$\begin{array}{l}\text { Unvaccinated children have higher probability of developing active TB and more severe clinical } \\
\text { forms of TB, meningitis, and miliary TB. }\end{array}$} & \\
\hline Immune status & \multicolumn{4}{|c|}{$\begin{array}{l}\text { The disease expression is directly linked to immune function. Neonates and infants have lower } \\
\text { capacity of APCs to present antigens to T cells. M. tuberculosis-ESAT-6- specific CD4+ T cells } \\
\text { number is lower in younger children ( } 0-3 \text { years old). Children }<5 \text { years old do not produce } \\
\text { IFN-g by CD8+ T cells in response to ESAT-6 and CFP-I0. }\end{array}$} & \\
\hline Coinfections & \multicolumn{4}{|c|}{$\begin{array}{l}\text { Fungal coinfections are frequent in primary immunodeficiency diseases that cause T cell } \\
\text { disorders and IL-I7 overexpression. Coinfections with non-tuberculous mycobacteria affect } 6 \% \\
\text { of children and may inhibit BCG vaccine effectiveness. Children < I5 years with HIV infection } \\
\text { at higher risk of TB infection and active TB development. Human cytomegalovirus coinfection } \\
\text { increases risk factors for TB infants. }\end{array}$} & \\
\hline $\begin{array}{l}\text { Genetic } \\
\text { immunodeficiencies }\end{array}$ & \multicolumn{4}{|c|}{$\begin{array}{l}\text { The Mendelian susceptibility to mycobacterial disease induces high susceptibility to infections. } \\
\text { NEMO and five autosomal genes: IFNGR (I and 2), STATI, ILI2B, and ILI2RBI, are involved in } \\
\text { the axes of IL-I2/IL-23-dependent and IFN-g-mediated immunity. }\end{array}$} & \\
\hline \multicolumn{5}{|c|}{ New immunological tools for diagnosis of TB } & \\
\hline RNA biomarkers & \multicolumn{4}{|c|}{$\begin{array}{l}\text { I0-transcript signature that distinguishes TB in children has } 97 \% \text { of sensitivity. In children }<15 \\
\text { years, a } 51 \text {-transcript signature of TB risk has } 82 \% \text { of sensitivity. }\end{array}$} & $93,94,96-99$ \\
\hline Immunophenotype & \multicolumn{4}{|c|}{$\begin{array}{l}\text { TAM-TB assay has a sensitivity of } 83 \% \text { and a specificity of } 97 \% \text {. MAIT cells are lower in children } \\
\text { with active TB. }\end{array}$} & \\
\hline MicroRNAs & \multicolumn{4}{|c|}{14 different miRNAs are down-regulated while miR-29 is up-regulated in children with TB. } & \\
\hline
\end{tabular}

(Continued) 
Table I (Continued).

\begin{tabular}{|c|c|c|c|c|c|}
\hline \multicolumn{5}{|c|}{ Standard Diagnosis of Pulmonary TB in Children } & \multirow[t]{2}{*}{ Ref. } \\
\hline & Clinical Features & $\begin{array}{l}\text { Microbiological } \\
\text { Tests Sensitivity }\end{array}$ & $\begin{array}{l}\text { DNA Tests } \\
\text { (Xpert MTB/ } \\
\text { RIF) } \\
\text { Sensitivity }\end{array}$ & $\begin{array}{l}\text { IFN-g Release } \\
\text { Assays (QFT- } \\
\text { Gold Sensitivity) }\end{array}$ & \\
\hline \multicolumn{5}{|c|}{ Hints for TB personalized diagnosis } & \\
\hline $\begin{array}{l}\text { Individual features } \\
\text { of disease }\end{array}$ & \multicolumn{4}{|c|}{$\begin{array}{l}\text { Age, metabolic or nutritional conditions, BCG vaccination, drug-sensitivity, and coinfections } \\
\text { could define the initial therapeutic regimens based on immunological evidence and support the } \\
\text { use of personalized medicine. }\end{array}$} & $104,120-123,127-131$ \\
\hline $\begin{array}{l}\text { Discrimination of } \\
\text { genetic conditions }\end{array}$ & \multicolumn{4}{|c|}{$\begin{array}{l}\text { Immunodeficiencies could be suspected within the clinical evaluation after BCG vaccination or } \\
\text { environmental mycobacteria infections, as well as recurrent or prolonged infections that do not } \\
\text { respond to adequate antibiotic therapy. }\end{array}$} & \\
\hline $\begin{array}{l}\text { Status of the } \\
\text { individual immune } \\
\text { response }\end{array}$ & \multicolumn{4}{|c|}{$\begin{array}{l}\text { Evaluation of TLRs, NLRs, IL-I2/IL- } 23 \text { axes, or redox status, can be used for the identification } \\
\text { of immunodeficiencies and immune markers response during infection, or to propose selected } \\
\text { immunoactivators. }\end{array}$} & \\
\hline
\end{tabular}

Note: Ghon focus: consisting of a granuloma, typically in the middle or lower zones of the lung.

Abbreviations: APC, antigen-presenting cells; TLR, Toll-like receptors; NLR, nucleotide-binding and oligomerization domain (NOD)-like receptors; NEMO, NF- $K B$ essential modulator; IGRAs, IFN- $\gamma$ release assays; MAIT, mucose-associated invariant T cells; TAM-TB, T-cell activation marker assay.

Additionally, $M$. tuberculosis Heparin-Binding Hemagglutinin (HBHA)-specific Th17 subsets have been associated with protection in children under three years, and ESAT-6-TNF- $\alpha+\mathrm{CD} 4+\mathrm{T}$ lymphocytes have been associated with active TB in children older than three years. ${ }^{2}$ The genomics of childhood TB revealed an association of an acquired immune defect with potential failing to contain the pathogen. ${ }^{35}$ Multiple genes with lower

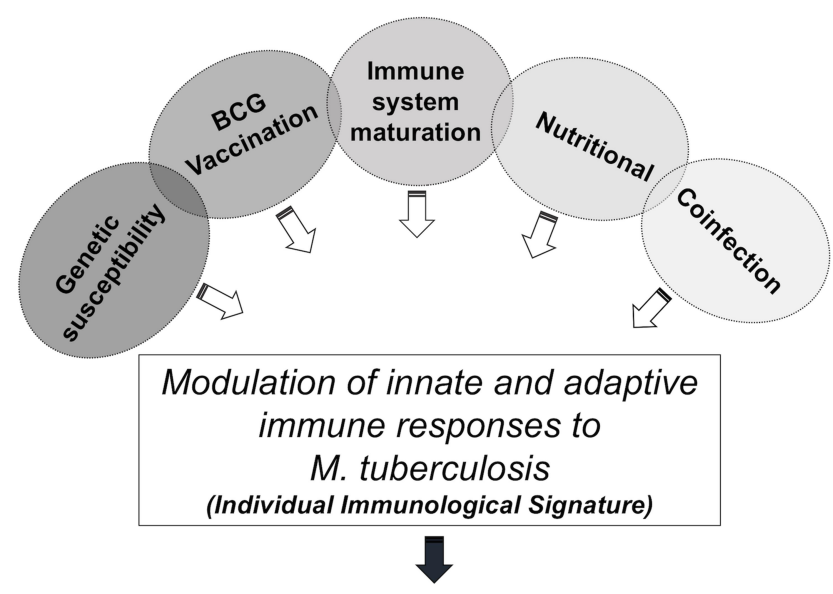

\section{Active TB in children}

Figure I Multifactorial external and internal stimuli influence the immunological signatures. Malnutrition, BCG vaccination status, immune system maturation (associated with age), genetic susceptibility (as Mendelian susceptibility to mycobacterial disease), and coinfection induce a specific immune signature and determine the fate of TB. transcript expression such as T-cell receptor and costimulatory molecules (CD3D, CD3G, TCR $\alpha$ ) and downstream signaling molecules (LAT, LCK, ITK, Ras-GRP, and NFAT) have been identified in children with acute TB, suggesting a defect in acquired immunity. ${ }^{25}$ Since innate and adaptive cellular immune responses and external factors are critical for the development of active TB, identifying specific immune responses as a signature will help resolve TB's main issues (Figure 1, Table 1).

\section{Coinfections Modify the Immune Response to TB in Children}

The host immune response induced by M. tuberculosis infection is modified by other concomitant infections caused by bacteria, viruses, and fungi. Once the antibiotic treatment of TB starts, fungal, viral, and non-tuberculosis mycobacterial infections are the most frequently diagnosed comorbidities. ${ }^{36}$ Other factors that may affect the immune response to $M$. tuberculosis are the extensive use of antibiotics or steroids, the presence of genetic immunodeficiencies, or chronic diseases. ${ }^{37}$ Thus, coinfections may change the immunological signature associated with TB and hinder the use of biomarkers associated with successful TB treatments.

Coinfections with non-tuberculous mycobacteria (NTM) include many environmental mycobacterial species such as M. avium complex, M. kansasii, M. abscessus, M. chelonae, 
M. fortuitum, M. terrae, M. xenopi, M. simiae, M. szulgai, and M. malmoense. NTM and M. tuberculosis share microbiological attributes, induce similar immune responses and have overlapping clinical manifestations. ${ }^{36}$ NTM account for $6 \%$ of cases in children investigated for pulmonary TB in South Africa. ${ }^{38}$ Additionally, it has been reported that high levels of exposure to NTM correlate with lower immune IFN- $\gamma$ responses to BCG vaccination, suggesting that NTM may inhibit BCG's effectiveness. ${ }^{39}$ Thus, coinfection with NTM suggests an impairment of the immune response in TB.

Coinfection with fungi is frequent in immunodeficiencies. For example, the chronic granulomatous disease is an inherited primary immunodeficiency disease that presents T cell disorders and IL-17 deficiencies, leading to increased susceptibility to mycobacterial and fungal infections, suggesting similarities in their immunopathogenesis. ${ }^{40}$ These fungal pulmonary infections may be primary and secondary in TB infection. ${ }^{37}$ The clinical symptoms of pulmonary TB coinfection overlap with those of some pathogenic fungi, including lung infection, metabolic features, innate immune receptors, and the ability to form granulomas. ${ }^{37}$ In many cases, overlooked fungal pulmonary infections due to the lack of specific clinical manifestations cause a high rate of morbidity and mortality. ${ }^{41}$ Candida albicans is the most prevalent fungal organism with the ability to cause infections, and prevalence of 15-32\% was reported in different studies of pulmonary TB coinfection with Candida sp. ${ }^{42}$ Other fungi, such as Aspergillus niger, A. fumigatus, Histoplasma capsulatum, and Cryptococcus neoformans are the leading causes of fatal lung infections in patients previously affected by pulmonary TB. ${ }^{43}$ Aspergillus sp. does not usually cause disease but, in immunocompromised patients or individuals who have had TB, it may cause severe disease. Given that the symptoms of chronic pulmonary aspergillosis are very similar to TB symptoms, it can often be misdiagnosed; unfortunately, the infection can grow steadily and undetected for years, and its treatment is rarely successful. Therefore, timely diagnosis of fungal diseases is of great importance when treating TB patients. ${ }^{44}$

Another human fungal disease is coccidioidomycosis, which may have similar clinical and radiologic presentations to TB but requires different treatment. Coinfection with TB and Coccidioides immitis is uncommonly reported, ${ }^{45}$ but it can also present as a life-threatening disease when the fungal cells disseminate to the skin, bone, and central nervous system. The outcome of coccidioidomycosis is determined mainly by the nature of the host immune response to the infection. ${ }^{46,47}$
Viral coinfections are common comorbidities in children with $\mathrm{TB}$; in children $<15$ years, HIV infection increases the risk of $\mathrm{TB}$ infection and the development of active TB. There are also changes in the host immune response in HIV coinfection. HIV infects cells of both the innate and adaptive immune system, such as CD4+ T cells, macrophages, dendritic cells, and neutrophils, and alter cytokines and chemokines production, which may impact on susceptibility to TB infection, progression and severity of the disease. ${ }^{48}$ Additionally, this susceptibility to TB infection with HIV coinfection has also been associated with myeloid-derived suppressor cells (MDSC), which can down-regulate $\mathrm{T}$ cell proliferation. Additionally, high levels of MDSC are present in HIV-exposed uninfected infants, who are known to have an increased susceptibility to $\mathrm{TB}$, suggesting a potential mechanism of these cells to trigger TB susceptibility. ${ }^{49}$

Influenza $\mathrm{A}$ virus and TB coinfection has been frequently identified among adults and children, and is associated with increased morbidity and mortality. ${ }^{50}$ Moreover, influenza-related alterations in the host immune response to $M$. tuberculosis have been reported in mice, as prior exposure to influenza A leads to enhanced mycobacterial growth and decreased survival. Following M. tuberculosis/ influenza virus coinfection, mycobacteria grow in a type I IFN signaling-dependent manner. ${ }^{51}$ However, a metaanalysis of 19 studies showed no conclusive results about severe influenza being a risk factor for increasing the prevalence of $\mathrm{TB}^{52}$

Chronic exposure to antigens from persistent viral or bacterial infections can result in sustained $\mathrm{T}$ cell activation and dysfunction of antigen-specific T cells. ${ }^{53}$ Human cytomegalovirus (HCMV) and Epstein-Barr virus (EBV) may also activate T cells. ${ }^{54,55}$ Moreover, both HCMV infection and immune activation have been identified as risk factors for TB. It is unknown whether other herpesviruses are also implicated in TB risk. ${ }^{56}$ However, there is epidemiological evidence of elevated HCMV-specific IgG in persons with $\mathrm{TB}$, and a link between increased latent and active HCMV infection has been reported in patients with TB and NTM disease. ${ }^{56-58}$ HCMV and immune activation have also been identified as risk factors for TB in infants, ${ }^{59}$ particularly in developing countries, such as sub-Saharan Africa, with high HCMV prevalence. $^{60}$ Interestingly, HCMVspecific IFN- $\gamma$ response has been associated with an increased risk of developing TB disease and shorter time to $\mathrm{TB}$ diagnosis. $\mathrm{HCMV}^{+}$infants who developed TB disease had lower expression of NK cell-associated gene 
signatures and a lower frequency of $\mathrm{CD} 3^{-} \mathrm{CD} 4^{-} \mathrm{CD} 8^{-}$lymphocytes $\mathrm{CD}^{-} 6^{-}$and $\mathrm{CD} 16^{+} \mathrm{NK}$ cells in infants who develop TB disease in the next 3 years when compared with $\mathrm{HCMV}^{+}$infants who do not develop disease. ${ }^{59}$ Understanding the interplay between TB and fungal and viral infections is essential to develop diagnostic methods based on immunological signatures in children with $\mathrm{TB}$ (Table 1).

\section{Advances in Immunodiagnostic Techniques for TB in Children}

Since 2016, the WHO alerted on the urgent need to develop diagnostic methods complementing the clinical diagnosis for TB in children, particularly in endemic countries with harsh socioeconomic conditions, where the disease may be underdiagnosed and associated with higher morbidity and mortality. Two main obstacles in the diagnosis of TB in children are the availability of adequate samples from respiratory secretions and the low number of bacilli present in such secretions. Indeed, more than two-thirds of all cases of TB in children are either not diagnosed or not reported, which may partially explain why $96 \%$ of the 239,000 children who died of TB in 2015 lacked treatment. ${ }^{61}$

Among infected children, the risk of developing the clinical disease is around $50 \%$ in infants and $25 \%$ in children between 2 and 5 years old. ${ }^{62}$ The diagnosis of TB in children continues to be a challenge both at the clinic and laboratory. Although testing based on host immune response looks promising, these technologies are still at an early stage. For example, none of them has proven to distinguish between latent and active TB disease or, even worse, between active TB and other respiratory infections.

The microbiologic diagnosis of TB has been traditionally based in smear microscopy and conventional cultures using solid media, such as Löwenstein-Jensen, and is still the gold standard for diagnosis. It usually involves a proactive search for high-quality samples from the infected site, which can include sputum, pleural effusions, lymph node aspirates, cerebrospinal fluid, tissue biopsies, gastric aspirates, and bronchoalveolar lavage.

Notwithstanding the prominent role of microbiological tests, culture time, positivity, and sensitivity continue to be major challenges. For example, the sensitivity of sputum smear microscopy, the most common technique, is less than $15 \%$. The sensitivity of cultures, although somewhat higher, rarely goes over $40 \%$, even on samples derived from gastric aspirates and induced sputum. ${ }^{63}$ While in adults with pulmonary $\mathrm{TB}$, positivity to acid-fast bacilli (AFB) staining of sputum smears can be as high as $75 \%$, it is only about $20 \%$ in children. ${ }^{64}$

It seems indisputable, therefore, the need to develop diagnostic tests that are rapid, sensitive, and specific enough to lead to an early diagnosis and treatment of children with both pulmonary and extrapulmonary forms of TB. Besides sputum smear and microbiological culture, the current approved diagnostic tools include DNA amplification tests, antibody or antigen detection systems, and IFN- $\gamma$ release assays (IGRA) (Figure 2, Table 1).

\section{DNA Amplification Tests}

Molecular tests such as polymerase chain reaction (PCR) are very sensitive, although they frequently require sending samples to distant referral laboratories. The Xpert MTB/RIF, and the new version Xpert MTB/RIF Ultra, are nucleic acid amplification tests. They are run in an automated real-time PCR system that simultaneously detects both $M$. tuberculosis complex and rifampicin resistance in less than two hours, which has proven more sensitive, specific, and rapid than traditional smear microscopy and cultures on solid media. However, it is subject to the same constraints related to the obtaining of adequate sputum samples. ${ }^{65}$ For this reason, several studies are evaluating M. tuberculosis detection in stool samples as an alternative, as it is less invasive and more convenient for young children. McLean et al recently published a review of nine studies performed on 1681 stool samples processed with the Xpert MTB/RIF, where a sensitivity of $67 \%$ and a specificity of $99 \%$ was reported against the standard microbiological reference tests. ${ }^{66}$

TrueNAT is a new chip-based in real-time PCR testing that detects TB bacilli in sputum in one hour. TrueNAT sensitivity is $96 \%$ compared to XpertMTB/RIF and $86 \%$ when compared to standard cultures. ${ }^{67}$ Some studies have found the sensitivity of XpertMTB/RIF and the new version, Xpert MTB/RIF Ultra, to be $63 \%$ and $74 \%$, respectively. ${ }^{68,69}$ The use of these technologies may improve detection rates of TB in the pediatric population (Table 1).

\section{Antibody Detection Tests}

Traditionally, antibody detection tests have been designed to detect antibodies against $M$. tuberculosis-secreted antigens in the serum of patients with active TB. Antibody detection has high specificity, but the sensibility depends on several factors. The type and number of antigens used for detection determine the test's sensibility; the more the 


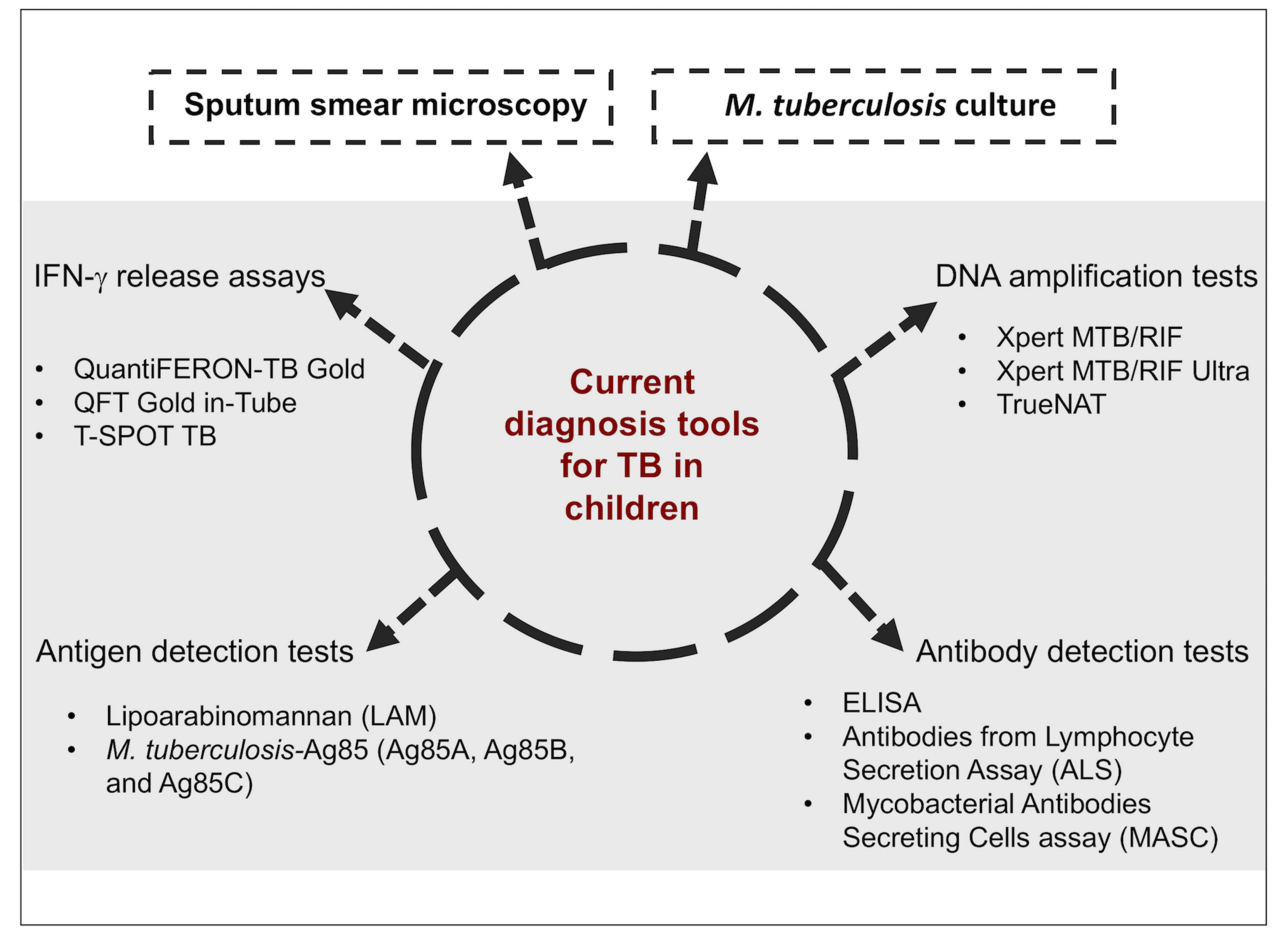

Figure 2 Current tools to diagnose TB in children. The traditionally denominated golden standards microbiological culture and sputum smear microscopy set the diagnosis in adults, but children are challenging to prove positive for either of them. Currently, diagnosis in children should include one or more of the more sophisticated techniques.

antigen's number, the higher the sensibility. ${ }^{70,71}$ The stage of the disease and the age of the patient also affect the sensibility of the test. Antibody detection has lower sensibility in children (25-44\%) than in adults $(52-85 \%)$, depending on the antigens used. This is probably associated with the children's paucibacillary condition; the test has a higher sensibility when the bacillary loads are higher. $^{72}$ Assessing humoral immune responses for 4 recombinant antigens significantly increases the sensibility of serodiagnosis of tuberculosis. ${ }^{73,74}$

The Antibodies from Lymphocyte Secretions assay (ALS) is a new serologic method to diagnose active TB and to assess treatment efficacy in children. ${ }^{75}$ ALS is based on the detection of BCG-IgG specific antibodies released by cultivated plasma cells from peripheral blood. In adult patients, ALS is highly sensitive and specific for the diagnosis of active TB. In children with clinically diagnosed TB, BCG-IgG levels derived from plasma cells were significantly higher than those in children without clinically active TB and healthy children. Concordance between ALS and clinical diagnosis was $72 \%$, although concordance was better for children older than five years. It was also observed that after six months of treatment, there was a significant decrease in ALS titles in all children with TB, suggesting that the test may be useful in monitoring therapeutic responses in children with $\mathrm{TB}^{76}$

Since humoral responses to mycobacterial antigens tend to be lower in children than in adults, the serological tests' sensitivity may be affected. However, the ALS assay, can leverage on a greater number of cells to yield higher IgG titers, which is an advantage over serum-based ELISAs. Furthermore, ALS titers are higher than average in subjects testing negative for the tuberculin skin test (TST), which suggests that B-cell function remains relatively unaffected. ALS, therefore, could be particularly useful in immunocompromised patients.

Mycobacterial Antibodies Secreting Cells assay (MASC) is another assay that measures a continuous immune activation of peripheral blood mononuclear cells against TB through conventional cultures deprived of antigenic stimulation. This assay has proven useful as a diagnostic tool for TB among adults. ${ }^{76,77}$ The MASC response, ferritin, and $\mathrm{C}$-reactive protein (CRP) were significantly higher in children with TB than in age-matched healthy controls. The sensitivity and specificity of MASC were $78 \%$ and $86 \%$, respectively, while its overall positive predictive value was $69 \%$. The sensitivity and specificity were $89 \%$ and $75 \%$ for ferritin, and $66 \%$ and $83 \%$ for CRP. Interestingly, MASC results are not affected by age, 
sex, or nutritional status. The authors recognize, however, that it is important to assess other candidate TB antigens to improve MASC's utility ${ }^{78}$ (Table 1).

\section{M. tuberculosis Antigen Detection Tests}

A few antigens of $M$. tuberculosis have been detected in blood, sputum, urine, gastric aspirates, and bronchoalveolar lavage. Lipoarabinomannan (LAM), a component of the M. tuberculosis cell wall, has been proposed as a biomarker of TB, but its sensitivity is low. ${ }^{79}$ The complex M. tuberculosis-Ag85 is a family of three proteins of 30-32 kD (Ag85A, Ag85B, and Ag85C). However, the detection of Ag85 in blood and urine yields highly variable results across several studies. ${ }^{80}$ Although LAM testing in urine is useful for the diagnosis of $\mathrm{TB}$ in adults, its value in children remains uncertain. In a South African study performed in children younger than 15 years with microbiologically confirmed TB infection, the sensitivity and the specificity of the test were low, and the authors recommended not to use it for the diagnosis of TB in children. ${ }^{81}$ In a study performed with 61 children younger than 14 years with clinically suspected TB in Indonesia, the detection of LAM in urine had a sensitivity of $83 \%$ and a specificity of $85 \%$, concluding that ELISA for urine LAM was a valuable diagnostic test for TB in children; ${ }^{82}$ however, in this study, only $42.9 \%$ of the subjects had microbiologically confirmed TB.

\section{IFN- $\gamma$ Release Assays}

Effector $\mathrm{T}$ cells react to $M$. tuberculosis antigens by producing IFN- $\gamma$. The widespread recognition of the critical role of IFN- $\gamma$ in the regulation of cell-mediated immune responses against $M$. tuberculosis has led to the development of interferon-gamma release assays (IGRA) for the diagnosis of $M$. tuberculosis infection. ${ }^{83}$ Two assays are commercially available: the QuantiFERONTB Gold and its more recent variant, the QuantiFERONTB Gold in-Tube (QFT-GIT), and the T-SPOT-TB. ${ }^{84}$ These assays measure IFN- $\gamma$ production in whole-blood in response to specific $M$. tuberculosis antigens like ESAT-6, CFP-10, and TB7.7. These assays are still controversial in children since the response of effector $\mathrm{T}$ cells is not as intense, probably due to the poorer clinical conditions of children with TB or their immature immune system.

The QFT-GIT assay has been evaluated in children in India. In one study, QFT-GIT showed a sensitivity of
$51.2 \%$ for detecting $M$. tuberculosis infection compared with $11 \%$ for solid culture, $12.1 \%$ for the tridimensional system BacT/ALERT, an automated microbial detection system based on liquid culture, $19.5 \%$ for Ziehl-Neelsen (acid-fast bacilli) staining, and $45.1 \%$ for PCR. ${ }^{85,86}$ Another study conducted in India evaluated the concordance between QFT-G and TST in children vaccinated with BCG, aged six months to 15 years, with suspected TB infection or as a contact of a patient with active TB. They did not find concordance between TST and QFTGIT, but the specificity for TST was twice that of QFTGIT. Because of the lack of concordance between those methods, and despite the cross-reactivity with environmental mycobacteria and BCG from vaccination, TST should remain the preferred test for M. tuberculosis in children living in endemic areas. ${ }^{87}$ In countries where newborn BCG vaccination is a routine, IGRA would be better to diagnose latent TB. On the other hand, it has been observed that IFN- $\gamma$ production as response to the mitogen of a positive control is lower in children younger than four years. ${ }^{88}$ Concordance of TST and QFT-GIT is low for children under four who have been vaccinated with BCG. These observations highlight the need for further studies in larger pediatric groups across several age ranges (Table 1).

The IFN- $\gamma$-induced Protein 10 (IP-10) is a chemokine expressed by many antigen-presenting cells. Viral and bacterial infections are known to be associated with IP-10 levels that are higher than IFN- $\gamma$, which suggests that it can be a promising diagnostic marker in some infectious diseases like TB. However, studies in children are still scarce. One was conducted to compare the ability of an IP-10 ELISA test to detect active and latent TB with that of QFT-GIT, and T-SPOT TB. The sensitivity of the latter two tests was $91.7 \%$ compared with $66.7 \%$ for the IP-10 assay. Based on data reported for IP-10 production versus IFN- $\gamma$ after stimulation by $M$. tuberculosis-specific antigens, ${ }^{89}$ the higher secretion of IP-10 should allow the use of smaller volumes of blood. Because it is a simple ELISA for a single analyte, it would make an easier-to-implement and less costly system at the laboratories. The performance of the IP-10 assay, QFT-GIT, and T-SPOT TB in diagnosing latent TB is similar. Thus, IP-10 could be used as a biomarker for TB in children, and the combination of these biomarkers could increase diagnostic tests' overall sensitivity. ${ }^{90}$ 


\section{New Immunological Tools for Diagnosis and Biomarkers Discovery}

The advancement of technological resources has provided a different set of tools to make a diagnosis while taking advantage of the immunological features for prognosis and biomarkers discovery. For a signature to become a biomarker, it should reliably indicate (or predict) biological conditions such as protective immunity, disease susceptibility, and pathology. ${ }^{91}$ Transcriptomics has contributed to the development of RNA diagnostic biomarkers; immunophenotyping has identified cellular markers for diagnosis and disease progression; and the discovery of microRNAs has identified signatures with diagnostic, predictive, and prognostic value in TB.

\section{RNA Biomarkers}

Ex-vivo analysis of RNA expression in host blood may represent a first step towards the identification of markers that could simplify the search for transcriptional signatures relevant to TB. Two recent studies conducted in India explored the value of the Dual-Color Reverse Transcriptase Multiplex Ligation-dependent Probe Amplification assay (dcRT-MLPA), which evaluates the expression of multiple genes with a sensitivity comparable to real-time qPCR at a lower cost, to identify diagnostic biomarkers across the whole spectrum of childhood TB and healthy household contacts. A total of 49 mRNA were analyzed from 127 blood samples from children between 6 months and 15 years. Compared with TST negative children (uninfected controls), children with microbiologically confirmed TB overexpressed seven genes (CD14, FCGR1A, FPR1, MMP9, RAB24, SEC14L1, and TIMP2) and showed downregulation of five more (BLR1, CD3E, CD8A, IL7R, and TGFBR2) establishing a diagnostic signature. They found biomarkers that differentiated between latent TB and active TB but not between latent TB and uninfected controls. ${ }^{77}$ The second study found a 10-transcript signature where GBP5, IFITM1/3, KIF1B, NLRP3, NOD2, and TNIP1 were up-regulated, while IFNG, NLRP1, TAGAP, and TGFBR2 were downregulated, and that distinguished TB in children from agematched healthy controls with a sensitivity and specificity higher than $97 \% .{ }^{92}$ Another study using a transcriptomic microarray, performed in African children younger than 15 years, reported a 51-transcript signature of TB risk that had a sensitivity and specificity of over $82 \%$. When compared to the Xpert MTB/RIF real-time PCR assay, which was highly specific, the transcriptional signature was more sensitive. ${ }^{93}$ This 51 -transcript signature also identified TB from other infectious diseases (Table 1). The applicability of transcriptional signatures to clinical care and patient management is only starting to be explored with many obstacles still to be overcome. Probably the most pressing is the requirement of costly devices that can detect multitranscript signatures.

\section{Immunophenotype}

Multiparametric flow cytometry allows the evaluation of the phenotype of the cells that contribute to the immune response against $\mathrm{TB}$, which has been proposed as a diagnostic tool. In a study conducted in Tanzanian children with symptoms of TB, cells from peripheral blood and sputum were obtained to assess the T-cell Activation Marker assay (TAM-TB). TAM-TB measures CD27 expression in IFN- $\gamma$-producing $\mathrm{CD} 4+\mathrm{T}$ cells that release IFN- $\gamma$ when stimulated by $M$. tuberculosis antigens like ESAT- 6 and CFP-10. The TAM-TB assay has a sensitivity of $83 \%$ and a specificity of $97 \%$. The clinical relevance of the TAM-TB assay lies in its ability to provide results in 24 hours and with a sensitivity comparable to that of M. tuberculosis culture. ${ }^{94}$

The Mucose-Associated Invariant $\mathrm{T}$ cells (MAIT) are innate, non-conventional $\mathrm{T}$ lymphocytes that express a partially invariant TCR (Va7.2-Ja33/20/12). Upon infection, MAIT cells quickly release pro-inflammatory cytokines such as IFN- $\gamma$, TNF- $\alpha$, and IL-17, promoting the activation of other cells. In healthy subjects, MAIT cells are abundant in peripheral blood, liver, respiratory, and intestinal mucosa. In the blood of patients with bacterial infections, they are less prevalent, ${ }^{95}$ suggesting their active recruitment at the site of infection. The exact role of MAIT cells in M. tuberculosis infection has not been elucidated. However, MAIT cells (defined as CD3+ CD4 - CD161high Va7.2+ T cells) are lower in children with active TB than in those with latent TB or healthy controls, suggesting that MAIT cells may be necessary for preventing TB disease progression in children $^{96}$ (Table 1). Immunophenotyping will contribute biomarkers for diagnosis in different stages of the disease.

\section{MicroRNAs}

Recent studies point out that microRNAs (miRNAs) are regulators of innate and adaptive immune responses against $M$. tuberculosis. MiRNAs could potentially have 
a diagnostic, predictive, and prognostic value in TB. Abnormal levels of miRNAs have been reported in adults infected by M. tuberculosis. To determine the diagnostic value of miRNA in children with TB, an analysis of 29 miRNAs revealed 14 of them as critical. Expression of miR-1, miR-155, miR-31, miR-146a, miR-10a, miR-25b, and miR-150 (as validated by RT-qPCR) was reduced, while expression of miR-29 was increased in children with TB compared with non-infected children. This study was one of the first studies to identify the circulating miRNA profile in children with TB and one of the first to suggest that miRNAs testing has the potential to become a novel, effective and non-invasive tool for early diagnosis of TB in children ${ }^{97,98}$ (Table 1).

\section{The Impact of Immune Status on Treatment Regimens}

Multiple therapeutic regimens have been evaluated in children, both in post-exposure prophylaxis and in disease treatment, but were never compared. Childhood exposure might only be treated with 6 to 9 months of daily isoniazid, four months of daily rifampicin, or three months of daily isoniazid and rifampicin, regardless of drug costs and adverse events in different country settings, where TB prevalence plays a determinant role in defining optimal prevention strategies. ${ }^{99}$ Drug safety and effectiveness in children also represent an information gap regarding the diversity of adult regimes for drug-sensitive and drugresistant TB. Diverse clinical forms in childhood TB enhance the treatment choice dilemma, suggesting that patients with isolated lymph node or pulmonary disease might require only a short treatment with few drugs; meanwhile, complicated or severe TB clinical forms might need a more prolonged therapy with more drugs. ${ }^{99-101}$ Preclinical models of each type of TB presentation, supported by new diagnostic tools, such as mass spectrometry, dynamic positron emission tomography bioimaging, and pharmacokinetic modeling, will give access to remarkable information for clinical trials design and development, solving the divergences in clinical decision making. ${ }^{102}$ Current guidelines for the management of TB in children contemplate regimes adjusted to sex, age, weight, and drug-sensitivity. ${ }^{103}$

Beyond the differences in demographics, drugsensitivity, and coinfections that define the initial therapeutic regimens, the building up of immunological evidence supports the use of personalized medicine.
The concept of personalized medicine develops the finer sub-classification of disease to add repeated monitoring of disease markers to enable tailoring of treatment to individual response incorporating a more precise biological stratification, that is finely adjusted to individual genetic and social factors. ${ }^{104}$ Some immunological traits were mentioned in the previous sections. Nonetheless, the initial immunological approach should include the evaluation of immune cell numbers and function, antibody and complement studies, and immunoglobulin levels to rule out primary immunodeficiencies syndromes. ${ }^{105}$

Specific immunological defects involved in response to TB have been extensively described, ${ }^{106-108}$ concluding that the IL-12/IL-23 axis is the most critical antimycobacterial response, but the involvement of other molecules such as CD40 and CD11c ${ }^{109}$ may also play a role in TB immunity. Other immune diseases, such as chronic granulomatous disease and hyper IgE syndrome, show a defective killing of intracellular pathogens related to reactive oxygen species production. ${ }^{106,107}$ These immunodeficiencies could be suspected within the clinical evaluation of "normal" mycobacterial infections, unusual localization, or unusual pathogen species of infectious diseases, as well as recurrent or prolonged infections that do not respond to adequate antibiotic therapy, ${ }^{106}$ and some of them can be addressed by supplementing with the recombinant form of the defective molecule.

One of the most recent advances in infectious diseases is the immune checkpoint blockade, extensively studied in cancer therapy. ${ }^{110}$ Some studies have focused on TB treatment, supporting a potential benefit of a monoclonal antibody blockade of Programmed death ligand-1 (PD-1), a specific $T$ cell molecule involved in response to $T B$ antigens (production of cytokines and proliferation of active circulating $\mathrm{T}$ and NK cells) whose inhibition would enhance mycobacterial clearance, limiting lung tissue damage. ${ }^{110}$ Immune blockades are particularly important in drug-resistant TB or HIV-TB patients, where IFN- $\gamma$, IL-2, and TNF- $\alpha$ are produced by TB-specific CD4+ $\mathrm{T}$ cells, and PD-1 blockade increased the number of regulatory $\mathrm{T}$ cells and recruited mesenchymal stem cells, ${ }^{111,112}$ whereas mucin domain-containing protein 3 (TIM3) blockade restored $\mathrm{T}$ cell function and improved mycobacterial control in infected mice. ${ }^{113}$

The treatment issues are usually focused on drug availability, lack of pediatric formulations, and trouble with patients' follow up and adherence to treatment. ${ }^{99,103,114}$ 
More clinical trials are needed to comprehend the extent of the effect of these therapies. Displaying the individual response to treatment, according to genetic, immunological, or environmental factors, would be valuable information for clinicians in order to consider drug changes, treatment duration, or the use of adjunct therapies. As the outcome of infection depends on the immune pathways activated by the pathogen, other factors affecting disease development should be taken into consideration in young children in high TBburden settings. For instance, the pre-existing environment, coinfections, and the sexually distinct activation pathways (ie, females elicit a more controlled response to Th1-inducing pathogens, and males, although generally immunesuppressive, are likely to elicit an exaggerated response to Th1-inducing pathogens), would likely impact the treatment outcome. $^{27}$ Probably a more generic immunomodulator approach, discussed in the following section, would address most of the disease conditions.

\section{Immunomodulators Towards Personalized TB Treatment}

Immunomodulatory agents are widely used in everyday practice to correct a patient's digressed immune functions. ${ }^{115}$ The overlong duration of treatment, potential drug toxicity, drug interactions with HIV medications, and increasing rates of drug resistance poses a challenge for TB treatment's efficacy. Therefore, strategies to accelerate recovery and reduce treatment duration are much needed. An example of such strategies is the development of adjunct immunotherapies. TB is often associated with immune dysregulation; thus, modulating immune reactivity is required to achieve the eradication of the pathogen and to prevent stable infection. ${ }^{116}$ Innate immunity activators are good candidates for this approach because they are predominantly immunostimulatory, and in this way, they would repair the immune dysregulation which develops in the patient. Nonetheless, very few trials have been conducted to evaluate the use of immunomodulators as an adjunct therapy in adult or childhood TB.

Probably, the most studied immunostimulant for TB is vitamin D. Several studies suggest that vitamin D plays an essential part in the treatment of TB as an adjunct to antimicrobial treatment because it decreases the duration and improves the effectiveness of treatment. ${ }^{117-119}$ Vitamin D represses IL-12 signaling, upregulates the expression of the antimicrobial peptide LL-37, which mediates M. tuberculosis killing, and promotes autophagy in a Toll-like receptors-dependent manner. ${ }^{120-122}$ In-vivo studies in humans have been unable to undoubtedly establish vitamin $\mathrm{D}$ as an effective immunostimulant for the eradication of $\mathrm{TB}$ in adults and children, probably because of the inconsistency in study designs. ${ }^{123-125}$ However, the general opinion is that vitamin D deficiency increases the risk of tuberculosis progression and that supplementation improves the immune response.

Different types of compounds and schemes have been tried in humans. A combination of BCG, diphtheria and tetanus vaccines, together with levamisole, has been used as an adjunct treatment for osteoarticular TB in patients unresponsive to standard chemotherapy. This immunotherapy was administered only for the initial eight weeks simultaneously with conventional antituberculosis therapy, and $70 \%$ of the patients had a clinical-radiological healing response by five months. ${ }^{126}$ Because of its antiinflammatory and immunomodulatory effects, thalidomide has been administered as an adjunct treatment in children with tuberculous meningitis, showing clinical improvement with potential anti-inflammatory effects, but there were not enough data to reach conclusive results. ${ }^{127}$ An immunomodulator derived from the pooled blood of HBV and HCV-positive donors, which following chemical and heat inactivation was formulated into an oral pill, was used as adjunct immunotherapy in recently-diagnosed, relapsed, and drug-resistant TB patients with a resultant clinical and radiological improvement, and negative smear conversion in $96.3 \%$ of the subjects. ${ }^{128}$

Childhood TB is difficult to diagnose, to treat, and to follow; probably, that is the reason for the lack of information regarding immunomodulation as an adjunct therapy. However, the importance of immunomodulators in children could be gathered from the treatment of recurrent respiratory tract infections (RRTIs). Children with RRTIs are a great challenge for physicians, from a therapeutic and preventive point of view, just like TB. The majority of children with RRTIs do not have recognized immunodeficiencies, but RRTIs may be attributed to their immature immune system and environmental factors. Therefore, immunomodulatory agents are widely used in these patients. $^{129}$ Several types of immunomodulators have been used in the treatment and prevention of RRTIs. A few include Imunoglukan $\mathrm{P} 4 \mathrm{H}^{\circledR}$, an insoluble $\beta$-glucan isolated from Pleurotusostreatus combined with vitamin C; ${ }^{115,129}$ Pidotimod (PDT, 3-L-pyroglutamylL-thiaziolidine-4-carboxylic acid), which is a synthetic dipeptide molecule exerting effects on both innate and 
adaptive immunity; ${ }^{130}$ and even probiotics have been used in children, adults and elderly patients with respiratory infections. ${ }^{131-133}$ All these immunomodulators are useful to activate the host immune system in both non-specific and specific way, thereby increasing resistance against invading pathogens, decreasing the frequency of flu and flu-like disease, and the number of lower respiratory tract infections, and reducing the relapses of RRTIs and the use of antibiotics.

Bacterial immunomodulators are other type of molecules widely used in clinical practice that, when administered orally, follow the route of naturally evoked mucosal immune responses. They are absorbed in the intestine generating the immune responses within mucosal tissues that extend to other organs including, lungs. ${ }^{134,135}$ Bacterial immunomodulators are commercially available as OM-85 BV (Broncho-Vaxom), LW 50020 (Luivac), ISMIGEN, and Ribosomal extract (Ribomunyl); they consist of bacterial cells killed and subjected to mechanical, chemical, or enzymatic lysis or of isolated bacterial organelles. Usually, they are mixtures of several bacterial species most frequently responsible for respiratory tract infections, including Staphylococcus aureus, Streptococcus pyogenes, S. viridans, S. mitis, S. pneumoniae, Klebsiella pneumoniae, K. ozaenae, Moraxella catarrhalis, Haemophilus influenzae, and Diplococcus pneumoniae. ${ }^{136,137}$ Depending on the dosage, formulation, and method of administration, bacterial immunomodulators activate the expression of proinflammatory cytokines in macrophages and monocytic cells, mainly IFN- $\gamma$, IL-2, IL-1, IL-6, IL- 8 , and TNF- $\alpha$, to activate NK cells and induce high levels of total and antigenspecific IgA, IgG and IgM, and induce the production of antimicrobial peptides. ${ }^{138-142}$ Bacterial lysate therapy reduces the frequency, duration, and severity of respiratory (upper and bronchopulmonary) tract infections, the frequency of asthma attacks, and the duration of coughing, wheezing, and use of antibiotics in children. ${ }^{137,143-146}$

Though very little has been done for childhood TB immunomodulation, bacterial immunomodulators are probably the most promising candidates in this regard. The main pending issues are that studies in healthy children are not available, high-quality clinical trials are needed, and each decision to initiate immunotherapy should be preceded by evaluating quantitative and functional efficacy of the immune system at the individual level, pointing again towards personalized medicine. We recently proposed a simple method to assess the immune status of children that could provide information on whether a patient should receive immunotherapy together with their standard antituberculosis regime. ${ }^{147}$ When immune profiles are available, it would be straightforward to determine whether a patient needs an immunostimulant, an immunosuppressor, or the supplementation of the absent immune effector.

\section{Concluding Remarks}

TB diagnosis is difficult in pediatric patients with the currently available microbiological tests. Since children are asymptomatic in most cases, diagnosis by clinical features is complicated. The efforts to find an ideal biomarker for TB diagnosis and treatment outcomes in children is a challenge; it should meet many criteria: 1) Be measurable in small volume samples that should be easily obtained, such as blood, urine, feces, or saliva. 2) Show high sensitivity and specificity for M. tuberculosis, regardless of age group, nutritional status, or coinfections. 3) Discriminate between children with active TB and those with a latent TB infection or other respiratory infections. 4) Be supported by multicentric, geographically diverse trials that include communities with high endemicity, so that tests found useful could be applied in multiple pediatric subpopulations. Unfortunately, no ideal biomarker exists, and it is complicated to find a biomarker that suits all cases because the immune signature is modified by a complex interaction of intrinsic and extrinsic factors like age and coinfections. Alternatively, a new strategy, based on personalized medicine, could be useful to evaluate specific molecules produced by the host immune response. With the transformation from the standard immunological signatures to personalized TB signatures, physicians could exert therapeutic decisions, including the use of immunomodulators as an adjunct therapy for each child.

\section{Abbreviations}

AFB, acid-fast bacilli; ALS, Antibodies from Lymphocyte Secretions assay; BCG, Calmette-Guerin bacillus; CFP, Culture Filtrate Protein-10; CRP, C-reactive protein; ESAT6, Early Secretion Antigen Target-6; HBHA, HeparinBinding Hemagglutinin; IFN- $\gamma$, interferon gamma; IGRA, IFN- $\gamma$ release assays; IL-IRA, interleukin 1 receptor antagonist; IP-10, IFN- $\gamma$-induced Protein 10; LAM, Lipoarabinomannan; MAIT, Mucose-Associated Invariant T cells; MASC, Mycobacterial Antibodies Secreting Cells assay; miRNAs, microRNAs; MSMD, Mendelian susceptibility to mycobacterial disease; M. tuberculosis, Mycobacterium tuberculosis; PD-1, Programmed death ligand-1; RBTIs, recurrent respiratory tract infections; 
TAM, T-cell Activation Marker; TB, tuberculosis; TIM3, mucin domain-containing protein 3 ; TNF- $\alpha$, tumor necrosis factor-alpha; TST, tuberculin skin test.

\section{Author Contributions}

All authors made a significant contribution to the work reported; took part in drafting, revising or critically reviewing the article; gave final approval of the version to be published; have agreed on the journal to which the article has been submitted; and agree to be accountable for all aspects of the work.

\section{Funding}

This work was supported by the National Institute for Respiratory Diseases Ismael Cosío Villegas.

\section{Disclosure}

The authors declare that there is no conflict of interest regarding the publication of this paper.

\section{References}

1. Moreno-Pérez D, Andrés Martín A, Altet Gómez N, et al. Diagnóstico de la tuberculosis en la edad pediátrica. Documento de consenso de la Sociedad Española de Infectología Pediátrica (SEIP) y la Sociedad Española de Neumología Pediátrica (SENP). Anales De Pediatría. 2010;73(3):143.e1-143.e14. doi:10.1016/j. anpedi.2009.12.017

2. Dreesman A, Corbière V, Dirix V, et al. Age-Stratified T cell responses in children infected with Mycobacterium tuberculosis. Front Immunol. 2017. doi:10.3389/fimmu.2017.01059

3. WHO. Https://Www.Who.Int/Biologicals/Areas/Vaccines/Bcg/En/.

4. WHO. Global Tuberculosis Report 2019; 2019.

5. Mellado Peña MJ, Santiago García B, Baquero-Artigao F, et al. Actualización del tratamiento de la tuberculosis en niños. An Pediatría. 2018;88(1):52.e1-52.e12. doi:10.1016/j. anpedi.2017.05.013

6. Thomas TA. Tuberculosis in Children. Thorac Surg Clin. 2019;29 (1):109-121. doi:10.1016/j.thorsurg.2018.09.009

7. Newton SM, Brent AJ, Anderson S, Whittaker E, Kampmann B. Paediatric tuberculosis. Lancet Infect Dis. 2008;8(8):498-510. doi:10.1016/S1473-3099(08)70182-8

8. Joosten SA, Fletcher HA, Ottenhoff THM, Helicopter A. Perspective on TB biomarkers: pathway and process based analysis of gene expression data provides new insight into TB pathogenesis. PLoS One. 2013. doi:10.1371/journal. pone. 0073230

9. Zar HJ, Workman LJ, Little F, Nicol MP. Diagnosis of Pulmonary Tuberculosis in Children: assessment of the 2012 National Institutes of Health Expert Consensus Criteria. Clin Infect Dis. 2015;61((Suppl 3)):S173-S178. doi:10.1093/cid/civ622

10. Zar HJ, Hanslo D, Tannenbaum E, et al. Aetiology and outcome of pneumonia in human immunodeficiency virus-infected children hospitalized in South Africa. Acta Paediatr Int J Paediatr. 2007;90(2):119-125. doi:10.1111/j.1651-2227.2001.tb00270.x

11. Perez-Velez CM, Marais BJ. Tuberculosis in children. $N$ Engl J Med. 2012;367(4):348-361. doi:10.1056/NEJMra1008049
12. Tuberculosis PNDE. Guía Práctica Para La Atención De La Tuberculosis En Niños, Niñas y Adolescentes.

13. Marais BJ, Gie RP, Schaaf HS, Beyers N, Donald PR, Starke JR. Childhood pulmonary tuberculosis: old wisdom and new challenges. Am $J$ Respir Crit Care Med. 2006;173 (10):1078-1090. doi:10.1164/rccm.200511-1809SO

14. Marais BJ, Gie RP, Hesseling AC, et al. A refined symptom-based approach to diagnose pulmonary tuberculosis in children. Pediatrics. 2006;118(5):e1350 LP-e1359. doi:10.1542/ peds.2006-0519

15. Ho TS, Wang SM, Shen CF, Lee KH, Liu CC. Clinical perspectives of childhood tuberculosis in Taiwan. J Formos Med Assoc. 2011;110(12):737-743. doi:10.1016/j.jfma.2011.11.002

16. Marais BJ, Gie RP, Obihara CC, Hesseling AC, Schaaf HS, Beyers N. Well defined symptoms are of value in the diagnosis of childhood pulmonary tuberculosis. Arch Dis Child. 2005;90 (11):1162-1165. doi:10.1136/adc.2004.070797

17. Nemir Rlee KK. Tuberculosis in children and adolescents in the 1980s. Pediatr Infect Dis J. 1988;7:6.

18. World Health Organization. No Title.

19. Marais BJ, Gie RP, Schaaf HS, et al. A proposed radiological classification of childhood intra-thoracic tuberculosis. Pediatr Radiol. 2004;34(11):886-894. doi:10.1007/s00247-004-1238-0

20. Piccini P, Chiappini E, Tortoli E, de Martino M, Galli L. Clinical peculiarities of tuberculosis. BMC Infect Dis. 2014;14(Supp1 1):1-12. doi:10.1186/1471-2334-14-S1-S4

21. Cruz AT, Hwang KM, Birnbaum GD, Starke JR. Adolescents with tuberculosis: a review of 145 cases. Pediatr Infect Dis $J$. 2013;32(9):937-941. doi:10.1097/INF.0b013e3182933214

22. Teeratakulpisarn J, Lumbiganon P, Pairojkul S, Jariyaviladkul P. Cavitary tuberculosis in a young infant. Pediatr Infect Dis. 1994;13(6):545-546. doi:10.1097/00006454-199406000-00018

23. American Thoracic Society. Diagnostic standards and classification of tuberculosis. Am Rev Respir Dis. 1990;142(3):725-735.

24. Turkova A, Welch SB, Paton JY, et al. Management of paediatric tuberculosis in leading UK centres: unveiling consensus and discrepancies. Int J Tuberc Lung Dis. 2014;18(9):1047-1056. doi:10.5588/ijtld.14.0094

25. Jaganath D, Mupere E. Childhood tuberculosis and malnutrition. J Infect Dis. 2012. doi:10.1093/infdis/jis608

26. Simon AK, Hollander GA, McMichael A. Evolution of the immune system in humans from infancy to old age. Proc $R$ Soc B Biol Sci. 2015. doi:10.1098/rspb.2014.3085

27. Seddon JA, Chiang SS, Esmail H, Coussens AK. The wonder years: what can primary school children teach us about immunity to mycobacterium tuberculosis? Front Immunol. 2018;9 (December). doi:10.3389/fimmu.2018.02946

28. Patel LN, Detjen AK. Integration of childhood TB into guidelines for the management of acute malnutrition in high burden countries. Public Heal Action. 2017. doi:10.5588/pha.17.0018

29. Thomas TA, Mondal D, Noor Z, et al. Malnutrition and helminth infection affect performance of an interferon $\gamma$-release assay. Pediatrics. 2010. doi:10.1542/peds.2010-0885

30. Newton SM, Brent AJ, Anderson S, Whittaker E, Kampmann B. Paediatric tuberculosis. Lancet Infect Dis. 2008. doi:10.1016/ S1473-3099(08)70182-8

31. Casanova JL, Abel L. Human genetics of infectious diseases: a unified theory. EMBO J. 2007. doi:10.1038/sj.emboj. 7601558

32. Lancioni C, Nyendak M, Kiguli S, et al. CD8 $+\mathrm{T}$ cells provide an immunologic signature of tuberculosis in young children. $A m$ $J$ Respir Crit Care Med. 2012. doi:10.1164/rccm.201107$1355 \mathrm{OC}$

33. Vanden Driessche K, Persson A, Marais BJ, Fink PJ, Urdahl KB. Immune vulnerability of infants to tuberculosis. Clin Dev Immunol. 2013. doi:10.1155/2013/781320 
34. Covián C, Fernández-Fierro A, Retamal-Díaz A, et al. BCGinduced cross-protection and development of trained immunity: implication for vaccine design. Front Immunol. 2019. doi:10.3389/fimmu.2019.02806

35. Hemingway C, Berk M, Anderson ST, et al. Childhood tuberculosis is associated with decreased abundance of $\mathrm{T}$ cell gene transcripts and impaired $\mathrm{T}$ cell function. PLoS One. 2017 doi:10.1371/journal.pone.0185973

36. Whittaker E, Lopez-Varela E, Broderick C, Seddon JA. Examining the complex relationship between tuberculosis and other infectious diseases in children: a review. Front Pediatr. 2019. doi: $10.3389 /$ fped.2019.00233

37. Osman NM, Gomaa AA, Sayed NM, Abd El Aziz AA. Microarray detection of fungal infection in pulmonary tuberculosis. Egypt J Chest Dis Tuberc. 2013. doi:10.1016/j. ejcdt.2013.02.002

38. Dhanasekaran S, Jenum S, Stavrum R, et al. Effect of non-tuberculous mycobacteria on host biomarkers potentially relevant for tuberculosis management. PLoS Negl Trop Dis. 2014. doi:10.1371/journal.pntd.0003243

39. Black GF, Dockrell HM, Crampin AC, et al. Patterns and implications of naturally acquired immune responses to environmental and tuberculous mycobacterial antigens in Northern Malawi. J Infect Dis. 2001. doi:10.1086/322042

40. Boisson-Dupuis S, Bustamante J, El-Baghdadi J, et al. Inherited and acquired immunodeficiencies underlying tuberculosis in childhood. Immunol Rev. 2015. doi:10.1111/imr.12272

41. Pfaller MA, Diekema DJ. Epidemiology of invasive candidiasis: a persistent public health problem. Clin Microbiol Rev. 2007. doi:10.1128/CMR.00029-06

42. Tuberculosis and fungal co-infection present in a previously healthy patient. Colomb Med. 2016.

43. Amiri MRJ, Siami R, Khaledi A. Tuberculosis Status and Coinfection of Pulmonary Fungal Infections in Patients Referred to Reference Laboratory of Health Centers Ghaemshahr City during 2007-2017. Ethiop J Health Sci. 2018. doi:10.4314/ejhs.v28i6.2

44. Guinea J, Torres-Narbona M, Gijón P, et al. Pulmonary aspergillosis in patients with chronic obstructive pulmonary disease: incidence, risk factors, and outcome. Clin Microbiol Infect. 2010. doi:10.1111/j.1469-0691.2009.03015.x

45. Naidu VG, Tammineni AK, Biscopink RJ, Davis TL, Veerabagu MP. Coccidioides immitis and Mycobacterium tuberculosis diagnosed by endoscopic ultrasound. J $S$ C Med Assoc. 2009.

46. Cole GT, Hung CY, Sanderson SD, et al. Novel Strategies to Enhance Vaccine Immunity against Coccidioidomycosis. PLoS Pathog. 2013. doi:10.1371/journal.ppat.1003768

47. Mitchell Magee D, Cox RA. Interleukin-12 regulation of host defenses against Coccidioides immitis. Infect Immun. 1996 doi:10.1128/iai.64.9.3609-3613.1996

48. Venturini E, Turkova A, Chiappini E, Galli L, de Martino M, Tuberculosis TC. HIV co-infection in children. BMC Infect Dis. 2014. doi:10.1186/1471-2334-14-S1-S5

49. Du Plessis N, Jacobs R, Gutschmidt A, et al. Phenotypically resembling myeloid derived suppressor cells are increased in children with HIV and exposed/infected with Mycobacterium tuberculosis. Eur J Immunol. 2017. doi:10.1002/eji.201646658

50. Walaza S, Tempia S, Dawood H, et al. The impact of influenza and tuberculosis interaction on mortality among individuals aged $\geq 15$ years hospitalized with severe respiratory illness in South Africa, 2010-2016. Open Forum Infect Dis. 2019. doi:10.1093/ ofid/ofz020

51. Redford PS, Mayer-Barber KD, McNab FW, et al. Influenza A virus impairs control of mycobacterium tuberculosis coinfection through a type $\mathrm{i}$ interferon receptor-dependent pathway. J Infect Dis. 2014. doi:10.1093/infdis/jit424
52. Walaza S, Cohen $\mathrm{C}$, Tempia $\mathrm{S}$, et al. Influenza and tuberculosis co-infection: a systematic review. Influenza Other Respi Viruses. 2020. doi:10.1111/irv.12670

53. Klenerman P, Hill A. T cells and viral persistence: lessons from diverse infections. Nat Immunol. 2005. doi:10.1038/ni1241

54. Wittkop L, Bitard J, Lazaro E, et al. Effect of cytomegalovirus-induced immune response, self antigen-induced immune response, and microbial translocation on chronic immune activation in successfully treated HIV type 1-infected patients: the ANRS CO3 Aquitaine Cohort. J Infect Dis. 2013. doi:10.1093/ infdis/jis 732

55. Gianella S, Anderson CM, Var SR, et al. Replication of human herpesviruses is associated with higher HIV DNA levels during antiretroviral therapy started at early phases of HIV Infection. $J$ Virol. 2016. doi:10.1128/jvi.02638-15

56. Stockdale L, Nash S, Farmer R, et al. Cytomegalovirus antibody responses associated with increased risk of tuberculosis disease in ugandan adults. J Infect Dis. 2020. doi:10.1093/ infdis/jiz581

57. Olaleye OD, Omilabu SA, Baba SS. Cytomegalovirus infection among tuberculosis patients in a chest hospital in Nigeria. Comp Immunol Microbiol Infect Dis. 1990. doi:10.1016/0147-9571(90) 90522-U

58. Amran FS, Kim K, Lim A, et al. Is Pulmonary non-Tuberculous Mycobacterial disease linked with a high burden of latent Cytomegalovirus? J Clin Immunol. 2016. doi:10.1007/s10875016-0233-1

59. Muller J, Tanner R, Matsumiya M, et al. Cytomegalovirus infection is a risk factor for TB disease in Infants. bioRxiv. 2017. doi: $10.1101 / 222646$

60. Adland E, Klenerman P, Goulder P, Matthews PC. Ongoing burden of disease and mortality from HIV/CMV coinfection in Africa in the antiretroviral therapy era. Front Microbiol. 2015. doi:10.3389/fmicb.2015.01016

61. Brigham DJ, Women's Hospital Y, et al. The Global Burden of Tuberculosis Mortality in Children: a Mathematical Modelling Study. 5.; 2017.

62. Organization WH. Global tuberculosis report 2013. 2013.

63. Kumar MK, Kumar P, Singh A. Recent advances in the diagnosis and treatment of childhood tuberculosis. J Nat Sci Biol Med. 2015;6(2):314-320. doi:10.4103/0976-9668.159988

64. Ruiz Jiménez M, Guillén Martín S, Prieto Tato LM, et al. “ Induced sputum versus gastric lavage for the diagnosis of pulmonary tuberculosis in children.". BMC Infect Dis. 2013;13 (1):222. doi:10.1186/1471-2334-13-222

65. Opota O, Mazza-Stalder J, Greub G, Jaton K. The rapid molecular test Xpert MTB/RIF ultra: towards improved tuberculosis diagnosis and rifampicin resistance detection. Clin Microbiol Infect. 2019;25(11):1370-1376. doi:10.1016/j. cmi.2019.03.021

66. MacLean E, Sulis G, Denkinger CM, Johnston JC, Pai M, Khana FA. Diagnostic accuracy of Stool Xpert MTB/RIF for detection of pulmonary tuberculosis in children: a Systematic Review and Meta-analysis. J Clin Microbiol. 2019;57:6. doi:10.1128/JCM.02057-18

67. Nikam C, Kazi M, Nair C, Jaggannath M, Shetty A, Rodrigues C. Evaluation of the Indian TrueNAT micro RT-PCR device with GeneXpert for case detection of pulmonary tuberculosis. 2014. doi:10.1016/j.ijmyco.2014.04.003

68. Nicol MP, Workman L, Prins M, et al. Accuracy of Xpert Mtb/Rif Ultra for the Diagnosis of Pulmonary Tuberculosis in Children. Pediatr Infect Dis J. 2018;37(10):e261-e263. doi:10.1097/ INF.0000000000001960

69. Nhu NTQ, Ha DTM, Anh ND, et al. Evaluation of Xpert MTB/ RIF and MODS assay for the diagnosis of pediatric tuberculosis. BMC Infect Dis. 2013. doi:10.1186/1471-2334-13-31 
70. Khan IH, Ravindran R, Yee JA, et al. Profiling antibodies to Mycobacterium tuberculosis by multiplex microbead suspension arrays for serodiagnosis of tuberculosis. Clin Vaccine Immunol. 2008;15(3):433-438. doi:10.1128/CVI.00354-07

71. Lyashchenko KP, Singh M, Colangeli R, Gennaro ML. A multi-antigen print immunoassay for the development of serological diagnosis of infectious diseases. J Immunol Methods. 2000;242(1-2):91-100. doi:10.1016/S0022-1759(00)00241-6

72. Senol G, Ecevit C, Öztürk A. Humoral immune response against 38- and 16-kDa mycobacterial antigens in childhood tuberculosis. Pediatr Pulmonol. 2009. doi:10.1002/ppul.20901

73. Bothamley G, Udani P, Rudd R, Festenstein F, Ivanyi J. Humoral response to defined epitopes of tubercle bacilli in adult pulmonary and child tuberculosis. Eur J Clin Microbiol Infect Dis. 1988. doi:10.1007/BF01964242

74. Pukazhvanthen P, Anbarasu D, Kabeer Basirudeen SA, Raja A, Singh M. Assessing humoral immune response of 4 recombinant antigens for serodiagnosis of tuberculosis. Tuberculosis. 2014. doi:10.1016/j.tube.2014.09.006

75. Raqib R, Mondal D, Karim MA, et al. Detection of antibodies secreted from circulating Mycobacterium tuberculosis-specific plasma cells in the diagnosis of pediatric tuberculosis. Clin Vaccine Immunol. 2009;16(4):521-527. doi:10.1128/CVI.0039108

76. Raqib R, Rahman J, Kamaluddin AKM, et al. Rapid Diagnosis of Active Tuberculosis by Detecting Antibodies from Lymphocyte Secretions. J Infect Dis. 2003;188(3):364-370. doi:10.1086/ 376511

77. Joosten SA, Goeman JJ, Sutherland JS, et al. Identification of biomarkers for tuberculosis disease using a novel dual-color RT-MLPA assay. Genes Immun. 2012;13(1):71-82. doi:10.1038/ gene. 2011.64

78. Iqbal NT, Ahmed K, Qamar FN, et al. Antibody-secreting cells to diagnose Mycobacterium tuberculosis infection in children in Pakistan. Achkar JM, ed. mSphere. 2020;5(1). doi:10.1128/ mSphere.00632-19

79. Minion J, Leung E, Talbot E, Dheda K, Pai M, Menzies D. Diagnosing tuberculosis with urine lipoarabinomannan: systematic review and meta-analysis. Eur Respir J. 2011;38 (6):1398-1405. doi:10.1183/09031936.00025711

80. Kashyap RS, Rajan AN, Ramteke SS, et al. Diagnosis of tuberculosis in an Indian population by an indirect ELISA protocol based on detection of Antigen 85 complex: a prospective cohort study. BMC Infect Dis. 2007;7. doi:10.1186/1471-2334-7-74

81. Nicol MP, Allen V, Workman L, et al. Urine lipoarabinomannan testing for diagnosis of pulmonary tuberculosis in children: a prospective study. Lancet Glob Heal. 2014;2:5. doi:10.1016/ S2214-109X(14)70195-0

82. Iskandar A, Nursiloningrum E, Arthamin MZ, Olivianto E, Chandrakusuma MS. The diagnostic value of urine lipoarabinomannan (LAM) antigen in childhood tuberculosis. J Clin Diagnostic Res. 2017;11(3):EC32-EC35. doi:10.7860/JCDR/ 2017/20909.9542

83. Bellete B, Coberly J, Barnes GL, et al. Evaluation of a WholeBlood Interferon- $\gamma$ release assay for the detection of mycobacterium tuberculosis infection in 2 study populations. Clin Infect Dis. 2002;34(11):1449-1456. doi:10.1086/340397

84. Di L, Li Y. The risk factor of false-negative and false-positive for T-SPOT.TB in active tuberculosis. J Clin Lab Anal. 2018;32(2). doi:10.1002/jcla.22273

85. Dogra S, Narang P, Mendiratta DK, et al. Comparison of a whole blood interferon- $\gamma$ assay with tuberculin skin testing for the detection of tuberculosis infection in hospitalized children in rural India. $J$ Infect. 2007;54(3):267-276. doi:10.1016/j. jinf.2006.04.007
86. Ängeby KAK, Werngren J, Toro JC, Hedström G, Petrini B, Hoffner SE. Evaluation of the BacT/ALERT 3D system for recovery and drug susceptibility testing of Mycobacterium tuberculosis. Clin Microbiol Infect. 2003;9(11):1148-1152. doi:10.1046/j.1469-0691.2003.00783.x

87. Seddon JA, Paton J, Nademi Z, et al. The impact of BCG vaccination on tuberculin skin test responses in children is age dependent: evidence to be considered when screening children for tuberculosis infection. Thorax. 2016;71(10):932-939. doi:10.1136/thoraxjnl-2015-207687

88. Shah I, Kathwate J, Shetty NS. Comparison of tuberculin skin test and QuantiFERON-TB Gold In-Tube test in Bacillus Calmette-Guerin-vaccinated children. Lung India. 2020;37 (1):24-29. doi:10.4103/lungindia.lungindia_304_19

89. Latorre I, Díaz J, Mialdea I, et al. IP-10 is an accurate biomarker for the diagnosis of tuberculosis in children. $J$ Infect. 2014;69 (6):590-599. doi:10.1016/j.jinf.2014.06.013

90. Zhang W. IP-10 for the diagnosis of tuberculosis in children. Medicine (Baltimore). 2019;98(23):e15977. doi:10.1097/ MD.0000000000015977

91. Jacobsen M, Mattow J, Repsilber D, Kaufmann SHE. Novel strategies to identify biomarkers in tuberculosis. Biol Chem. 2008;389:5. doi:10.1515/BC.2008.053

92. Gjøen JE, Jenum S, Sivakumaran D, et al. Novel transcriptional signatures for sputum-independent diagnostics of tuberculosis in children. Sci Rep. 2017;7(1):1-9. doi:10.1038/s41598-017-05057$\mathrm{x}$

93. Anderson ST, Kaforou M, Brent AJ, et al. Diagnosis of childhood tuberculosis and host RNA expression in Africa. $N$ Engl $J$ Med. 2014;370(18):1712-1723. doi:10.1056/NEJMoa1303657

94. Portevin D, Moukambi F, Clowes P, et al. Assessment of the novel T-cell activation marker-tuberculosis assay for diagnosis of active tuberculosis in children: a prospective proof-of-concept study. Lancet Infect Dis. 2014;14(10):931-938. doi:10.1016/ S1473-3099(14)70884-9

95. Ghazarian L, Caillat-Zucman S, Houdouin V. Mucosal-associated invariant $\mathrm{T}$ cell interactions with commensal and pathogenic bacteria: potential role in antimicrobial immunity in the child. Front Immunol. 2017;8(DEC). doi:10.3389/fimmu.2017.01837

96. Malka-Ruimy C, Ben YG, Lambert M, et al. Mucosal-associated invariant $\mathrm{T}$ cell levels are reduced in the peripheral blood and lungs of children with active pulmonary tuberculosis. Front Immunol. 2019;10(FEB). doi:10.3389/fimmu.2019.00206

97. Zhou M, Yu G, Yang X, Zhu C, Zhang Z, Zhan X. Circulating microRNAs as biomarkers for the early diagnosis of childhood tuberculosis infection. Mol Med Rep. 2016;13(6):4620-4626. doi:10.3892/mmr.2016.5097

98. Wang JX, Xu J, Han YF, Zhu YB, Zhang WJ. Diagnostic values of microRNA-31 in peripheral blood mononuclear cells for pediatric pulmonary tuberculosis in Chinese patients. Genet Mol Res. 2015;14(4):17235-17243. doi:10.4238/2015.December.16.23

99. Reuter A, Hughes J, Furin J. Challenges and controversies in childhood tuberculosis. Lancet. 2019;394(10202):967-978. doi:10.1016/S0140-6736(19)32045-8

100. Harausz EP, Garcia-Prats AJ, Law S, et al. Treatment and outcomes in children with multidrug-resistant tuberculosis: a systematic review and individual patient data meta-analysis. PLoS Med. 2018;15(7):1-26. doi:10.1371/journal.pmed.1002591

101. Seddon JA, Weld ED, Schaaf HS, Garcia-Prats AJ, Kim S, Hesseling AC. Conducting efficacy trials in children with MDR-TB: what is the rationale and how should they be done? Int $J$ Tuberc Lung Dis. 2018;22(5):24-33. doi:10.5588/ ijtld.17.0359

102. Tucker EW, Dooley KE. Preclinical tools for the evaluation of tuberculosis treatment regimens for children. Int $J$ Tuberculosis Lung Dis. 2018;22(5):7-15. doi:10.5588/ijtld.17.0354 
103. Khatami A, Britton PN, Marais BJ. Management of Children with Tuberculosis. Clin Chest Med. 2019;40(4):797-810. doi:10.1016/ j.ccm.2019.08.003

104. Day S, Coombes RC, McGrath-Lone L, Schoenborn C, Ward H. Stratified, precision or personalised medicine? Cancer services in the 'real world' of a London hospital. Sociol Health Illn. 2017;39 (1):143-158. doi:10.1111/1467-9566.12457

105. Chicago $U$ of. Evaluation for Immunologic Deficiency Syndromes.

106. Lee W, Huang J-L, Yeh K, et al. Immune defects in active mycobacterial diseases in patients with primary immunodeficiency diseases (PIDs). J Formos Med Assoc. 2011;110 (12):750-758. doi:10.1016/j.jfma.2011.11.004

107. Boisson-Dupuis S, Bustamante J, El-Baghdadi J, et al. Inherited and acquired immunodeficiencies underlying tuberculosis in childhood. Immunol Rev. 2015;264(1):103-120. doi:10.1111/ imr. 12272

108. Filipe-Santos O, Bustamante J, Chapgier A, et al. Inborn errors of IL-12/23- and IFN- $\gamma$-mediated immunity: molecular, cellular, and clinical features. Semin Immunol. 2006;18(6):347-361. doi:10.1016/j.smim.2006.07.010

109. Hambleton S, Salem S, Bustamante J, et al. IRF8 mutations and human dendritic-cell immunodeficiency. N Engl J Med. 2011;365 (2):127-138. doi:10.1056/NEJMoa1100066

110. Rao M, Valentini D, Dodoo E, Zumla A, Maeurer M. Anti-PD-1/ PD-L1 therapy for infectious diseases: learning from the cancer paradigm. Int J Infect Dis. 2017;56(2017):221-228. doi:10.1016/ j.ijid.2017.01.028

111. Wykes MN, Lewin SR. Immune checkpoint blockade in infectious diseases. Nat Rev Immunol. 2018;18(2):91-104. doi:10.1038/nri.2017.112

112. Tousif S, Singh Y, Prasad DVR, Sharma P, van Kaer L, Das G $\mathrm{T}$ cells from programmed death-1 deficient mice respond poorly to mycobacterium tuberculosis infection. PLoS One. 2011;6:5. doi:10.1371/journal.pone.0019864

113. Jayaraman P, Jacques MK, Zhu C, et al. TIM3 Mediates T cell exhaustion during Mycobacterium tuberculosis Infection. PLoS Pathog. 2016;12(3):1-21. doi:10.1371/journal.ppat.1005490

114. Gröschel MI, van den Boom M, Migliori GB, Dara M. Prioritising children and adolescents in the tuberculosis response of the WHO European Region. Eur Respir Rev. 2019;28 (151):180106. doi:10.1183/16000617.0106-2018

115. Jesenak M, Majtan J, Rennerova Z, Kyselovic J, Banovcin P, Hrubisko M. Immunomodulatory effect of pleuran ( $\beta$-glucan from Pleurotus ostreatus) in children with recurrent respiratory tract infections. Int Immunopharmacol. 2013;15(2):395-399. doi:10.1016/j.intimp.2012.11.020

116. Grange JM, Brunet LR, Rieder HL. Immune protection against tuberculosis - When is immunotherapy preferable to vaccination? Tuberculosis. 2011;91(2):179-185. doi:10.1016/j. tube.2010.12.004

117. Ralph AP, Kelly PM, Anstey NM. L-arginine and vitamin D: novel adjunctive immunotherapies in tuberculosis. Trends Microbiol. 2008;16(7):336-344. doi:10.1016/j.tim.2008 04.003

118. Wejse C, Gomes VF, Rabna P, et al. Vitamin D as supplementary treatment for tuberculosis: a double-blind, randomized, placebo-controlled trial. Am J Respir Crit Care Med. 2009;179 (9):843-850. doi:10.1164/rccm.200804-567OC

119. Martineau AR, Wilkinson RJ, Wilkinson KA, et al. A single dose of vitamin $\mathrm{D}$ enhances immunity to mycobacteria. Am J Respir Crit Care Med. 2007;176(2):208-213. doi:10.1164/rccm.200701$007 \mathrm{OC}$

120. Liu PT. Toll-Like Receptor Triggering of a Vitamin D-mediated human antimicrobial response. Science (80-). 2006;311 (5768):1770-1773. doi:10.1126/science.1123933
121. Yuk J-M, Shin D-M, Lee H-M, et al. Vitamin D3 induces autophagy in human Monocytes/Macrophages via Cathelicidin. Cell Host Microbe. 2009;6(3):231-243. doi:10.1016/j. chom.2009.08.004

122. Gynther P, Toropainen S, Matilainen JM, Seuter S, Carlberg C, Väisänen S. Mechanism of 1 1 ,25-dihydroxyvitamin D3dependent repression of interleukin-12B. Biochim Biophys Acta - Mol Cell Res. 2011;1813(5):810-818. doi:10.1016/j. bbamcr.2011.01.037

123. Gou X, Pan L, Tang F, Gao H, Xiao D. The association between Vitamin D status and tuberculosis in children: a meta-analysis. Med (United States). 2018. doi:10.1097/MD.0000000000012179

124. Aibana O, Huang CC, Aboud S, et al. Vitamin D status and risk of incident tuberculosis disease: a nested case-control study, systematic review, and individual participant data meta-analysis. PLoS Med. 2019. doi:10.1371/journal.pmed.1002907

125. Wu HX, feng XX, Zhu M, Wei J, Zhuo KQ, yun CD. Effects of vitamin D supplementation on the outcomes of patients with pulmonary tuberculosis: a systematic review and meta-analysis. BMC Pulm Med. 2018. doi:10.1186/s12890-018-0677-6

126. Arora A, Nadkarni B, Dev G, et al. The use of immunomodulators as an adjunct to antituberculous chemotherapy in non-responsive patients with osteo-articular tuberculosis. $J$ Bone Jt Surg - Ser B. 2006;88(2):264-269. doi:10.1302/0301620X.88B2.17197

127. Schoeman JF, Springer P, Ravenscroft A, et al. Adjunctive thalidomide therapy of childhood tuberculous meningitis: possible anti-inflammatory role. J Child Neurol. 2000;15(8):497-503. doi:10.1177/088307380001500801

128. Butov DA, Pashkov YN, Stepanenko AL, et al. Phase IIb randomized trial of adjunct immunotherapy in patients with first-diagnosed tuberculosis, relapsed and multi-drug-resistant (MDR) TB. J Immune Based Ther Vaccines. 2011;9:1-9. doi:10.1186/1476-8518-9-3

129. Jesenak M, Urbancikova I, Banovcin P. Respiratory tract infections and the role of biologically active polysaccharides in their management and prevention. Nutrients. 2017;9(7):1-12. doi:10.3390/nu9070779

130. Niu H, Wang R, Jia Y T, Cai Y. Pidotimod, an immunostimulant in pediatric recurrent respiratory tract infections: a meta-analysis of randomized controlled trials. Int Immunopharmacol. 2019;67 (October 2018):35-45. doi:10.1016/j.intimp.2018.11.043

131. Leyer GJ, Li S, Mubasher ME, Reifer C, Ouwehand AC. Probiotic Effects on Cold and Influenza-Like Symptom Incidence and Duration in Children. Pediatrics. 2009;124(2): e172-e179. doi:10.1542/peds.2008-2666

132. de Vrese M, Winkler P, Rautenberg P, et al. Probiotic bacteria reduced duration and severity but not the incidence of common cold episodes in a double blind, randomized, controlled trial. Vaccine. 2006;24(44-46):6670-6674. doi:10.1016/j. vaccine.2006.05.048

133. Guillemard E, Tondu F, Lacoin F, Schrezenmeir J. Consumption of a fermented dairy product containing the probiotic Lactobacillus casei DN-114 001 reduces the duration of respiratory infections in the elderly in a randomised controlled trial. $\mathrm{Br}$ J Nutr. 2010;103(1):58-68. doi:10.1017/S0007114509991395

134. G-J VD, van 'T Veen A, So KL, et al. Oral Immunization with polyvalent bacterial lysate and infection with streptococcus pneumoniae: influence on interferon-gamma and PMN Elastase Concentrations in Murine Bronchoalveolar Lavage Fluid. Int Arch Allergy Immunol. 1992;97(2):173-177. doi:10.1159/ 000236114

135. Pasquali C, Salami O, Taneja M, et al. Enhanced mucosal antibody production and protection against respiratory infections following an orally administered bacterial extract. Front Med. 2014;1(OCT):1. doi:10.3389/fmed.2014.00041 
136. Jurkiewicz D, Zielnik-Jurkiewicz B. Bacterial lysates in the prevention of respiratory tract infections. Otolaryngol Pol $=$ Polish Otolaryngol. 2018;72(5):1-8. doi:10.5604/01.3001.0012.7216

137. Esposito S, Bianchini S, Polinori I, Principi N. Impact of OM-85 given during two consecutive years to children with a history of recurrent respiratory tract infections: a retrospective study. Int J Environ Res Public Health. 2019;16(6):1-8. doi:10.3390/ ijerph16061065

138. Keul R, Roth M, Papakonstantinou E, Nauck M, Perruchoud AP, Block LH. Induction of interleukin 6 and interleukin 8 expression by Broncho-Vaxom (OM-85 BV) via C-Fos/serum responsive element. Thorax. 1996;51(2):150-154. doi:10.1136/thx.51.2.150

139. Ruedl C, Fruhwirth M, Wick G, Wolf H. Immune response in the lungs following oral immunization with bacterial lysates of respiratory pathogens. Clin Diagn Lab Immunol. 1994;1 (2):150-154. doi:10.1128/cdli.1.2.150-154.1994

140. Bousquet J, Oliveri D. Role of Ribomunyl?? in the Prevention of Recurrent Respiratory Tract Infections in Adults. Treat Respir Med. 2006;5(5):317-324. doi:10.2165/00151829-200605050-00003

141. Roth M, Pasquali C, Stolz D, Broncho Vaxom TM. OM-85) modulates rhinovirus docking proteins on human airway epithelial cells via Erk1/2 mitogen activated protein kinase and cAMP. PLoS One. 2017. doi:10.1371/journal.pone.0188010

142. Yin J, Xu B, Zeng X, Shen K. Broncho-Vaxom in pediatric recurrent respiratory tract infections: a systematic review and meta-analysis. Int Immunopharmacol. 2018. doi:10.1016/j. intimp.2017.10.032
143. Lu Y, Li Y, Xu L, Xia M, Cao L. Bacterial lysate increases the percentage of natural killer $\mathrm{T}$ cells in peripheral blood and alleviates asthma in children. Pharmacology. 2015;95(3-4):139-144. doi:10.1159/000377683

144. Be D, Fj E, Flenady V, Jjl S. Immunostimulants for preventing respiratory tract infection in children (Review) Summary of findings for the main comparison. 2011;(6):2-4. doi:10.1002/ 14651858.CD004974.pub2.www.cochranelibrary.com

145. Esposito S, Bianchini S, Bosis S, et al. A randomized, placebo-controlled, double-blinded, single-centre, Phase IV trial to assess the efficacy and safety of OM-85 in children suffering from recurrent respiratory tract infections. J Transl Med. 2019;17 (1):1-9. doi:10.1186/s12967-019-2040-y

146. Bellanti JA, Olivieri D, Serrano E. Ribosomal Immunostimulation. BioDrugs. 2003;17(5):355-367. doi:10.2165/00063030-200317050-00005

147. Carreto-Binaghi LE, Juárez E, Guzmán-Beltrán $\mathrm{S}$, et al. Immunological evaluation for personalized interventions in children with tuberculosis: should it be routinely performed? J Immunol Res. 2020. doi:10.1155/2020/8235149

\section{Publish your work in this journal}

Infection and Drug Resistance is an international, peer-reviewed openaccess journal that focuses on the optimal treatment of infection (bacterial, fungal and viral) and the development and institution of preventive strategies to minimize the development and spread of resistance. The journal is specifically concerned with the epidemiology of antibiotic resistance and the mechanisms of resistance development and diffusion in both hospitals and the community. The manuscript management system is completely online and includes a very quick and fair peerreview system, which is all easy to use. Visit http://www.dovepress.com/ testimonials.php to read real quotes from published authors. 